\title{
Home range, movement and habitat selection of dholes (Cuon alpinus) in Khao Yai National Park, Thailand
}

\author{
RONGLARP SUKMASUANG ${ }^{1, \vartheta}$, WARONG SUKSAVATE ${ }^{1}$, NUCHARIN SONGSASEN ${ }^{2}$, \\ NORASET KHIOWSREE ${ }^{1}$, KHWANRUTAI CHARASPET ${ }^{1}$, MANANYA PLA-ARD ${ }^{1}$, \\ YUWALUK CHANACHAI ${ }^{1}$, WARISARA THOMAS ${ }^{1}$, KHANCHIT SRINOPAWAN ${ }^{3}$ \\ ${ }^{1}$ Department of Forest Biology, Faculty of Forestry, Kasetsart University. 50 Phahonyothin Road, Chatuchak District, Bangkok 10900, Thailand. \\ Tel.: +66-2-579-0176, Fax.: +66-2-942-8107, `email: mronglarp@ gmail.com. \\ ${ }^{2}$ Smithsonian's National Zoo \& Conservation Biology Institute. 3001 Connecticut Ave., NW, Washington, DC 20008, USA \\ ${ }^{3}$ Khao Yai National Park. PO 4, Pakchong District, Nakhon Ratchasima Province, Thailand
}

Manuscript received: 3 November 2020. Revision accepted: 29 November 2020.

\begin{abstract}
Sukmasuang R, Suksavate W, Songsasen N, Khiowree N, Charaspet K, Pla-ard M, Chanachai Y, Thomas W, Srinopawan K. 2020. Home range, movement and habitat selection of dholes (Cuon alpinus) in Khao Yai National Park, Thailand. Biodiversitas 21: 5915-5926. This study aimed to examine the home range, movement and habitat selection of dholes (Cuon alpinus) in Khao Yai National Park from January 2017 to September 2019 with the objective of studying their movement, diel activity and habitat selection. Based on Autocorrelated Kernel density home range estimation, the results showed that the average home range size of the adult female dhole was $64.6 \mathrm{~km}^{2}$, while the adult male dhole had an average home range size of $132.9 \mathrm{~km}^{2}$. It was found from the monthly analysis that the home range size varied by animal gender and the period of their denning and parenting time. It was also found that the distance traveled by the female dhole was $10.2 \mathrm{~km} /$ day, while the male dhole traveled around $19.3 \mathrm{~km} / \mathrm{day}$. The overall analysis discovered that the dholes were most active during dawn and dusk. Further, the level of activity increased from May onwards. The grassland and mixed deciduous habitat types significantly affected the selection of the dholes. Case-control linear logistic regression analysis between the distance of the location and habitat types was extremely and positively significant with grassland, which signified the high activity of dhole in the grassland. However, the result was negative with mixed deciduous forest, which was the habitat of the dhole. Autocorrelation functions demonstrated high activity occurred during the early morning and after sunset, which showed that the dholes could adapt for survival in the area, even with recreational activities in the park. The results of this study could contribute to knowledge concerning the species' movement for long-term species management and conservation.
\end{abstract}

Keywords: Dhole, Dong Phayayen-Khao Yai Forest Complex, habitat selection, home range, movement, satellite collar

\section{INTRODUCTION}

Understanding animal movement and space use across landscapes is critical for the establishment of effective conservation strategies (Allen and Singh 2016). Including the creation and maintenance of ecological corridors designed to ensure the movement of the species, the connectivity of habitat patches within fragmented landscapes can be improved, while priority areas for conservation can be identified (Morato et al. 2016). In the case of dholes, the species plays a unique role in the Asian ecosystem, both as an ecological indicator and as a regulator. Dholes, as a significant predator more due to their pack structure than individual size, require large numbers of prey to survive. They are highly sensitive to changes in prey base and habitat quality (Acharya et al 2010). The dhole is a dominant predator species within Khao Yai National Park, a part of the Dong Phaya YenKhao Yai World Heritage Area in Thailand (Ngoprasert and Gale 2019). Kamler et al. (2012) reported that the minimum land requirements for a sustainable dhole population are probably larger than that for any other Asian terrestrial mammal. Populations of dholes require five times more land area than populations of tigers (Panthera tigris) for long-term persistence. Thus, understanding the home range and movement of the dhole provides useful ecological knowledge for wildlife habitat management.

Dholes, as an endangered species of wild dog, are medium-sized carnivorous wild animals that have physiological evolution, including structures and tooth alignment similar to other hypercarnivorous mammals (Srivathsa et al. 2014). Normally, they live in packs. At present, most populations live in the forests of Southeast Asia, South Asia, Central Asia, and East Asia, including Central China, countries in the Himalayas, countries in the Tibetan Plateau, and Southern Russia (Kamler et al. 2015). Dholes can hunt alone or in packs (Kamler et al. 2015) depending on the size of the prey. Living as a pack of dholes is also beneficial in helping to raise their pups (Asa and Valdespino 1998). The members of dhole packs are genetically related to the others that live together (Bekof 1984). Dholes are important as consumers in the ecosystem. However, they are at risk of becoming extinct because of the small numbers of the remaining population (Kamler et al. 2015). The adult population in the wild is estimated at only 949-2,215 (Kamler et al. 2015). Despite this fact, dholes are carnivorous mammals that have received little study focus in the world (Acharya et al. 
2010; Kamler et al. 2015) when compared with other carnivorous mammals. In particular, studies of the home range and movement by wildlife radio telemetry tracking need to be conducted for management benefit (Harestad and Bunnell, 1979).

An investigation by radio telemetry tracking is generally used to track wildlife that is difficult to see and has mysterious activity, especially carnivorous mammals. The results of such a study provide information that cannot be obtained from other means. It is also useful for understanding natural history for effective conservation (Gutema 2015). In the case of dholes, the species has a clear mating season and denning period (Davidar 1974; Durbin et al., 2004; Acharya et al., 2010). They typically copulate once a year during the mating season (Kamler et al. 2015). In India, there have been reports that the mating season for dholes runs from December to February (Davidar 1974), while the mating season for dholes on Java island, Indonesia, runs from January to May (Durbin et al., 2004). Female dholes that are breeding will have a gestation period of roughly nine weeks (Sosnovskii 1967). Mothers and members of the pack help to raise the pups. For the two months after the females give birth, the male dholes and members of the pack will hunt for food and protect the territory (Asa and Valdespin 1998). Davidar (1974) found that three mothers can contribute to feeding 1 litter of dholes. When the mothers raise a litter alone, they may not succeed. Johnsingh (1979) reported that female dholes that live alone and breed outside the pack would often not succeed in raising the pups. Normally, the litter size is 5-10 pups (Venkataraman et al. 1995). Dhole pups wean when they are two months old (Durbin et al., 2004). From previous studies, dholes spend five months to copulate during the mating season, mate, then find and use dens until their babies leave the den from December to April. However, Acharya et al. (2010) reported that the denning season for dholes in India is from December to February. The pre-denning season for dholes is August to November, while the post-denning season is March to July. Meanwhile, Durbin et al. (2004) reported that the mating season for dholes in India is November to April, and the peak time is December to January (Davidar 1974). The minimum convex polygon (MCP) (Mohr 1947) and kernel density estimators (KDE) are the most commonly used tools to estimate animal home ranges (Gregory 2017). A process that assumes uncorrelated positions and velocities could underestimate the extent of the animal movement. Recent approaches, such as fitting continuous-time stochastic movement models to animal tracking data, can account for inherent serial autocorrelation (Morato et al. 2016). Movement analyses using this method have several desirable properties, including the ability to handle irregular sampling schedules and complex autocorrelation structures (Calabrese et al., 2016). This approach includes variogram analysis, which allows models to incorporate movement features to strictly fit to the data (Morato et al. 2016). Once an appropriate continuous-time variogram model has been selected and fit, Autocorrelated Kernel Density Estimation (AKDE) then conditions the fitted model to allow accurate home range estimation, even when data is strongly autocorrelated (Fleming and Calabrese 2017). Calabrese et al. (2016) gave a detailed account of using the continuous-time movement modeling package (ctmm) in $\mathrm{R}$ to perform this sequence of analyses. The study of home range, movement characteristics, and habitat selection of dholes can fulfill the ecological knowledge as an important basis for conservation and greatly affect the area management.

The objectives of the study are to investigate the home range and movement between sexes, including the diel activity period, of dholes found in Khao Yai National Park to improve understanding of the endangered species for the benefit of population management, habitat, public relations for the conservation of species, and further studies.

\section{MATERIALS AND METHODS}

\section{Khao Yai National Park (KYNP)}

KYNP (Thailand) is located between $14^{\circ} 5^{\prime}-14^{\circ} 15^{\prime} \mathrm{N}$ and $101^{\circ} 5^{\prime}-101^{\circ} 50^{\prime} \mathrm{E}$ and covers $2,168 \mathrm{~km}^{2}$ along with the Phanom Dong Rak mountain range from the central to northeastern regions. It is an important source for many rivers, such as the Nakhon Nayok River and Moon River. The park is part of the Dong Phayayen-Khao Yai Forest Complex that was declared a World Natural Heritage site in 2005 because of its diversity of wildlife, comprising a habitat of more than 800 vertebrates including 112 species of mammals, 392 species of birds, and more than 200 species of reptiles and amphibians. Among these are four endangered species, 19 vulnerable species, and one critically endangered species (UNESCO 2019). Most of the forest is comprised of dry evergreen forest, tropical rain forest, and hill evergreen forest. Besides, there is a mixed deciduous forest and grassland from shift farming in the past (National Parks Research and Innovation Development Centre (NPRD) 2017). The study area is between Khao Yai Forest Fire Control Station and Khao Yai Training Centre, which covers an area of $70 \mathrm{~km}^{2}$ approximately. Data taken from Khao Yai National Park recorded by the measuring point at Mosingto reveal mean annual rainfall for the past decade (2008-2017) of 1,897.1 $\mathrm{mm}$, with the maximum monthly average value recorded in September $(353.44 \mathrm{~mm}$ ) during a rainy season from May to October. For temperature at the same site, the average annual figure is $21.3^{\circ} \mathrm{C}$ with the high coming in April $\left(30.3^{\circ} \mathrm{C}\right)$ and the low in January $\left(12.3^{\circ} \mathrm{C}\right)$ (NPRD 2017). Figure 1 presents the topographic map of the KYNP and also shows GPS locations for the collared dholes in the study area. 


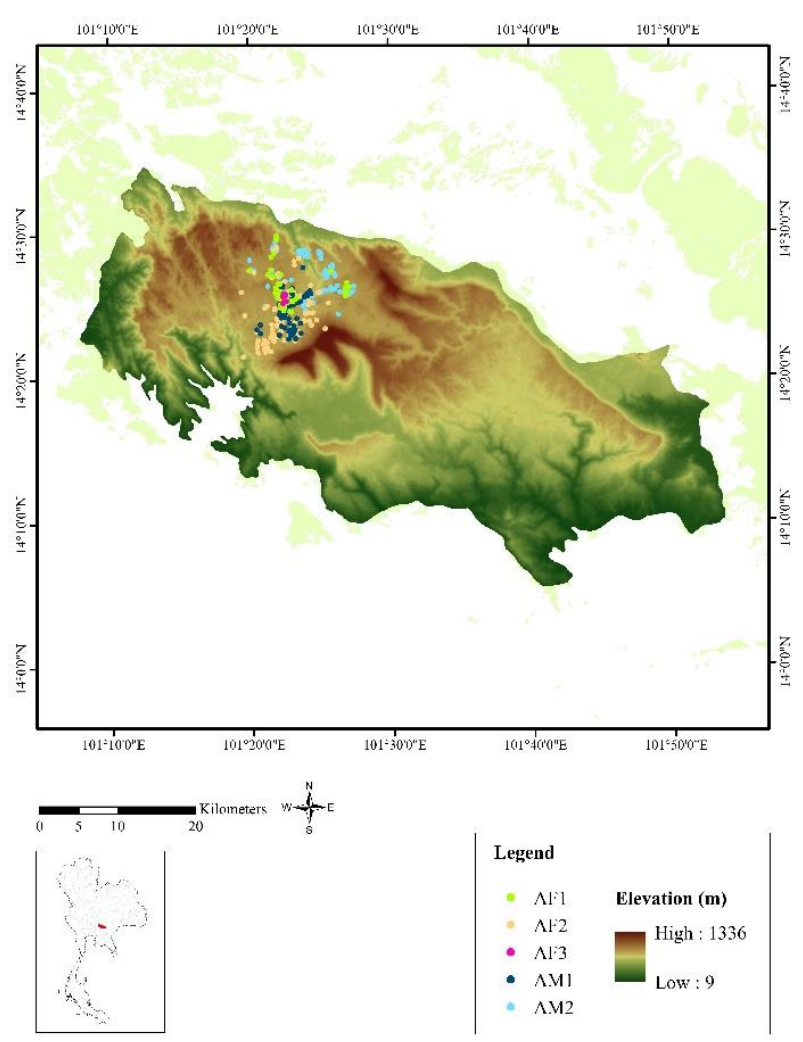

A

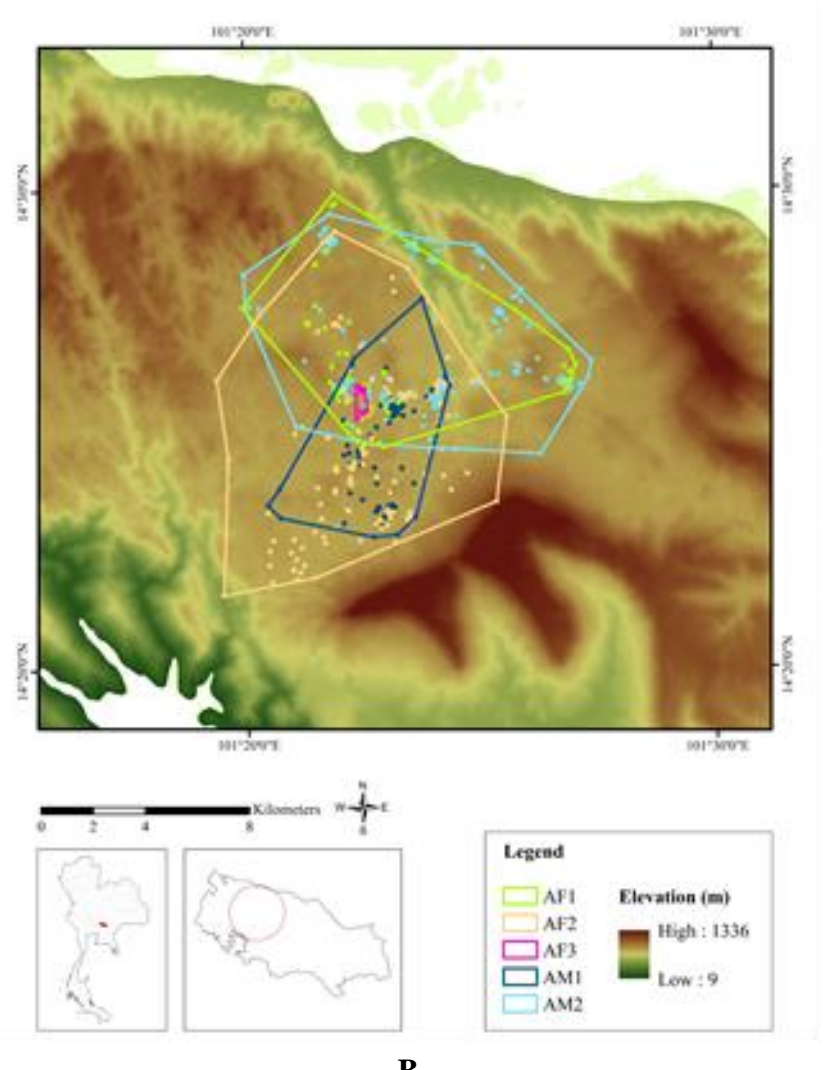

B

Figure 1. A. Location and general elevation map of Khao Yai National Park, Nakhon Ratchasima, Thailand; B. Collared dots show GPS locations for the collared dholes

\section{Dhole trapping and data collection}

Dhole trapping was performed using soft-catch traps placed in the study area. Five to eight trap stations were established in the area between January and February. Based on the camera trap survey using directed observation during the study in the field, three dhole packs were identified. Attempts to capture the dhole and radio-collar them to represent each pack were carried out. To capture the dholes, we used Oneida Victor \#1 1/2 soft-catch leg-hold traps (Minnesota Trapline Products, Pennock, MN, USA). Each trap station comprised 9-11 leg-hold traps, using meat from cattle as bait. At every trap site, a motion-triggered VHF transmitter was positioned in order to obtain a record of the time when the traps were sprung. The transmitter signals were checked at fifteen-minute intervals continuously throughout the duration of the study period as a means of ensuring that the trapped animals would not be harmed. Cameras were also positioned at each of the trapping sites to allow the researchers to identify the animal species visiting the trap to take the bait. Trapped dholes were anesthetized using a mixture of tiletamine and zolazepam (Telazol) at an amount of $10 \mathrm{mg} / \mathrm{kg}-1$ (Jenks et al. 2012). The age of the dholes was clarified by teeth erosion, while gender, health, and pregnancy were identified by external appearances and some characteristics of body measurements, as shown in Appendix Table 1. We examined each immobilized dhole for general body condition, determined its sex and age, collected its weight, and fit it with a global positioning system collar. Animals were released at the site of capture.

The satellite collars were designed specifically for dholes, consisting of 2 collars from the Sirtrack brand and 3 collars from the Lotex Litetrack Iridium 360 brand $(450 \mathrm{~g}$ weight). The collar was welded with an elastic sheet that could come off by itself over time; the battery life of the collar was about 1 year. The collars were set to send signals every 2 hours to register the date, time, and location, which could be downloaded from the websites for Sirtrack and Lotex. The data was converted to standard time in Thailand. Moreover, there was a VHF signal installed in the collars of the dholes to track the locations in the area, 34 days per month throughout the study period by receiving the signal.

\section{Data analysis \\ Home range estimation}

To determine the area of use around dhole dens, we first examined space use, focusing on the early denning period (November-January), including the parturition period until pups were 5 weeks old (Davidar 1974). We calculated home ranges for individual dhole employing 50\% contours as a means of defining the core area, and $95 \%$ contours in order to specify the designated home range surrounding each den (Hinton et al. 2016). The home ranges were calculated using an autocorrelated kernel density estimator (AKDE) (Fleming and Calabrese 2017) and applying the ctmm 0.3.2 package (Calabrese et al. 2016; Fleming and Calabrese 2017) using $\mathrm{R}$ version 3.3 .2 software. The 
AKDE technique applies a semi-variance approach which is able to take into consideration the fact that relocation data will be inherently autocorrelated since any locations which are closely linked in time will be similarly close in space. AKDE can support the estimation of the autocorrelation structure by fitting a movement model to the location data. From this estimate, it is then possible to determine the optimal bandwidth. The problem with standard approaches is that the autocorrelation is ignored, leading to underestimates of the home range size (Fleming et al. 2015). By following the approach of Calabrese at al. (2016) in creating AKDEs, a semivariogram function is visually fitted to the variogram for the recorded movement of each individual dhole.

In accordance with the location data we obtained, comprising IID (independently identically distributed), Ornstein-Uhlenbeck foraging (OUF), and OrnsteinUhlenbeck (OU), we fitted the more appropriate of two different versions of the movement model: isotropic for general movement patterns, or anisotropic for directional data. The top-ranked model was then selected using Akaike's information criterion with correction to take into account the small sample size (AICc) which was obtained from the ctmm function ctmm. select. In the IID model it is assumed that the locations and velocities are not correlated (equivalent to kernel density estimation), but in the case of the OUF and OU models, the movement described is directed towards a central position, such as the center of the home range of the dhole. The OUF and OU models both present a description of the use of limited space, such as the dholes' residency within their home range. However, there is no correlation between OUF and velocity but this is not the case for OU (Calabrese et al. 2016). The OU and OUF models are both able to provide estimates for the size of the home range and the position autocorrelation time, which is usually understood to be the home range crossing time. Averaged probability density functions of the utilization distributions obtained from dholes which had been fitted with radio collars served to determine the home ranges for each of the dhole packs. The monthly home ranges for each pack could also be determined through the use of $95 \%$ minimum convex polygons (MCP) (Mohr and Stumpf 1966) facilitated by the rhr package (Signer and Balkenhol 2015 ) in $\mathrm{R}$. The analyses were all conducted using AKDEcalculated home ranges.

For each animal, we plotted the sample semi-variance and fitted the data to a predefined semi-variogram function with the likelihood approach. The most suitable model was then selected using AIC to visually inspect the autocorrelation structure between locations and time lag. Velocity autocorrelation was determined using the nonlinear trend of semi-variogram at a short time lag. Space utilization was investigated by inspecting semi-variogram at longer time lags for the asymptotic point, which roughly corresponded to the travelling time to cover the home range of the range resident.

\section{Diel activity pattern}

To analyze the diel activity pattern of dholes from the movement data, the movement rate was used as a proxy for diel dhole activity pattern to test for the influence of time on the speed of locomotion. The movement rate every 2 hours from the hourly positions was calculated using the Euclidean distance of the preceding 2-hour time step. The population-level pattern in diel movement rate was modeled with generalized additive mixed models (GAMMs) using the mgcv package (Wood 2019). The GAMMs were implemented to fit the movement rate response using the negative binomial family with cyclic cubic regression spline smooth function (Tamminga et al. 2016) to represent the diel cyclic pattern according to the hour of the day. The random intercept was incorporated to represent the repeated measurements of individual dholes across the study and compare diel activity between male and female dholes.

\section{Habitat selection pattern}

We used ArcMap 10.2.1 (ESRI, Redlands, CA) to conduct all spatial analyses. Dhole habitat selection was analyzed using matched case-control logistic regression (CCLR) with a stratum of 1-per-3 sampling design (Fortin et al. 2005). At every start location for the movement step, there were 3 available end locations randomly sampled with replacement based on step-length and turning angle across individuals. CCLR was used to estimate the probability of a movement step selection between the 5hour intervals of the successive straight-line segment. The covariates of CCLR model consisted of estimated diel activity pattern and environmental covariates based on surrounding land cover represented by the effects of Euclidean distance between each type of land cover. CCLR analyses and model selection were performed in $\mathrm{R}$ ( $\mathrm{R}$ Core Team 2017) using the SURVIVAL and glmulti packages (Calcagno 2020), respectively.

\section{RESULTS AND DISCUSSION}

\section{Home range estimation}

Five adult dholes, 2 adult males and 3 adult females were captured and radio-collared. The details of some measurements, date of the each animal was captured and tagged with radio collar, and number of days that can be received the signal was shown in Appendix table 1.

The average home range size of the 3 adult female dholes, at $95 \%$ Kernel density estimation, was $64.6 \mathrm{~km}^{2}$. The average home range size of the 2 adult males, when analyzed at $95 \%$ Kernel estimation, was $132.9 \mathrm{~km}^{2}$, which clearly shows that the size of the home range for the adult male dhole was approximately twice as larger than that for the female when considering both the new analysis method and MCP, as detailed in Table 1.

Scatter plots of all GPS locations and home range characteristics for the 5 collared dholes individually in KYNP based on AKDE method are shown in Figure 2. Variograms of the 5 collared dholes based on AKDE method are shown in Figure 3. It should be noted that the animal's semi-variance reaches an asymptote within 1 to 15 days depending on the denning period. This roughly represents the time to cross its home range; the shading represents the $95 \% \mathrm{CL}$. 
Table 1. The home range calculated based on the 95\% KDE, 95\% Autocorrelated Kernel Density Estimation (AKDE) of adult dholes analyzed by the overall data in Khao Yai National Park, Thailand

\begin{tabular}{|c|c|c|c|c|c|c|c|c|c|c|c|}
\hline & \multirow{2}{*}{$\begin{array}{l}\text { Sex } \\
\text { and } \\
\text { age }\end{array}$} & \multirow[b]{2}{*}{ N1 } & \multirow{2}{*}{$\begin{array}{l}\text { Home range } \\
\text { crossing day } \\
\text { (d) }\end{array}$} & \multirow{2}{*}{$\begin{array}{l}\text { Velocity auto- } \\
\text { correlated time } \\
\text { scale (minute) }\end{array}$} & \multirow{2}{*}{$\begin{array}{l}\text { Average } \\
\text { distance } \\
\text { travelled } \\
\text { (km/day) }\end{array}$} & \multicolumn{3}{|c|}{$\operatorname{MCP}\left(\mathbf{k m}^{2}\right)$} & \multicolumn{3}{|c|}{ 95\% AKDE $\left(\mathrm{km}^{2}\right)$} \\
\hline & & & & & & $50 \%$ & $75 \%$ & $95 \%$ & Low & Estim. & High \\
\hline \multicolumn{12}{|l|}{ Female } \\
\hline Adult female dhole (AF 1) & $\mathrm{AF}$ & 178 & 1.7 & NA & NA & 12.5 & 26.0 & 70.5 & 49.6 & 74.8 & 105.1 \\
\hline Adult female dhole (AF 2) & $\mathrm{AF}$ & 256 & 2.4 & NA & NA & 14.0 & 32.1 & 70.5 & 30.9 & 69.4 & 123.3 \\
\hline Adult female dhole (AF 3) & $\mathrm{AF}$ & 57 & 0.2 & NA & NA & 0.05 & 0.1 & 0.5 & 29.4 & 49.6 & 74.9 \\
\hline Average & & & & & & & & & 36.6 & 64.6 & 101.1 \\
\hline \multicolumn{12}{|l|}{ Male } \\
\hline Adult male dhole (AM 1) & $\mathrm{AM}$ & 190 & 1.8 & NA & NA & 27.5 & 55.0 & 125.0 & 97.2 & 127.7 & 162.4 \\
\hline Adult male dhole (AM 2) & $\mathrm{AM}$ & 459 & 2.5 & 22.8 & 19.0 & 33.0 & 65.9 & 124.3 & 4.1 & 132.9 & 192.6 \\
\hline Average & & & & & & & & & 4.1 & 132.9 & 192.6 \\
\hline
\end{tabular}

Note 1: Number of telemetry locations

\section{Monthly home range}

The size of the monthly home range showed that the estimated average monthly home range of the first adult female was $23.9 \mathrm{~km}^{2}$ when analyzed using Autocorrelated Density Estimation $\left(\right.$ AKDE) $\left(\right.$ range $=6.7-37.9 \mathrm{~km}^{2}$ ). The second adult female dhole had an estimated average home range size of $73.5 \mathrm{~km}^{2}\left(\right.$ range $\left.=50.0-103.4 \mathrm{~km}^{2}\right)$. The home range size of the third female dhole was $42.4 \mathrm{~km}^{2}$ (range = 1.6-83.2 $\mathrm{km}^{2}$ ). The home range size of the first male was $40.4 \mathrm{~km}^{2}$ (range $=10.5-70.2 \mathrm{~km}^{2}$ ), while the second male dhole had a home range size of $74.3 \mathrm{~km}^{2}$ (range $=47.6$ $97.6 \mathrm{~km}^{2}$ ), as detailed in the analysis results in Table 2 .

The results from the analysis with MCP revealed that the home range size was smaller than that of the analysis with AKDE. Wilcoxon signed-rank test did not find a significant difference when comparing the monthly home range sizes of males and females during the study period, both calculated with $\mathrm{MCP}(\mathrm{Z}=1.88, \mathrm{P}=0.058)$ and $\mathrm{AKDE}$ $(\mathrm{Z}=-0.76, \mathrm{P}=0.45)$. The movement of dholes calculated for the first female dhole in April was 10.2 kilometers/day. The movement of male dholes calculated in February was 19.3 kilometers/day, and it was 1.9 kilometers/day in April.

The study of home range habitat for the second female dhole ran from January to June. It was the only dhole studied thoroughly from the denning period, between January and April, to the post-denning period (Durbin et al. 2004). The average home range habitat of the second female dhole during the denning period was $33.6 \mathrm{~km}^{2}$, while that of the female dhole during the post-denning period was $48.5 \mathrm{~km}^{2}$. The calculation of home range size for the second female dhole included the post-denning period, which was normally enlarged from the denning period when the dhole hunted near its habitat to facilitate its parental duty. This explained why the results showed that the home range habitat of the second female dhole was bigger than that of the first and third female dholes.
The comparison between the average home range habitat of male dhole and that of the first and third female dholes in the same denning period from January to April showed that the average home range habitat of the male dhole was larger $\left(60.7 \mathrm{~km}^{2}\right)$ than that of the female dhole $\left(45.0 \mathrm{~km}^{2}\right)$, as shown in Table 2 .

\section{Distance of movement, diel activity and habitat selection pattern \\ Distance of movement}

Based on AKDE, the distance of movement per day could only be analyzed for 2 dholes: the first female dhole and the second male dhole. The analysis found that the average distance travelled $(\mathrm{km} /$ day) by the first female dhole during April was $10.2 \mathrm{~km}$ /day (range 8.2-12.2 $\mathrm{km} /$ day), while the distance travelled by the second male dhole in February was $19.3 \mathrm{~km} /$ day (16.9-21.7 km/day) (see Table 2). In the case of the overall analysis, only the second male dhole resulted in a distance of movement at $19.0 \mathrm{~km} /$ day (range 14.8-23.1 km/day) (see Table 1).

\section{Diel activity}

Analysis results of diel movement for the collared dholes during the day found that the maximum value was around $20.00 \mathrm{hrs}$. The average moving speed was high in the early morning (04.00 hrs.) and after sunset, while the average moving speed was somewhat lower in the afternoon and evening (Figure 4 and Figure 5). The estimated activity pattern from GAMMs also found that the male dholes had a higher average moving speed than the females, as shown in Figure 5 and Figure 6. The analysis of the movement using Generalised Additive Mixed Models (GAMM) revealed that the monthly movement of dholes tended to increase after April to a peak in July. After that, it tended to decline before entering a new circle in the following year, as shown in Figure 6. 


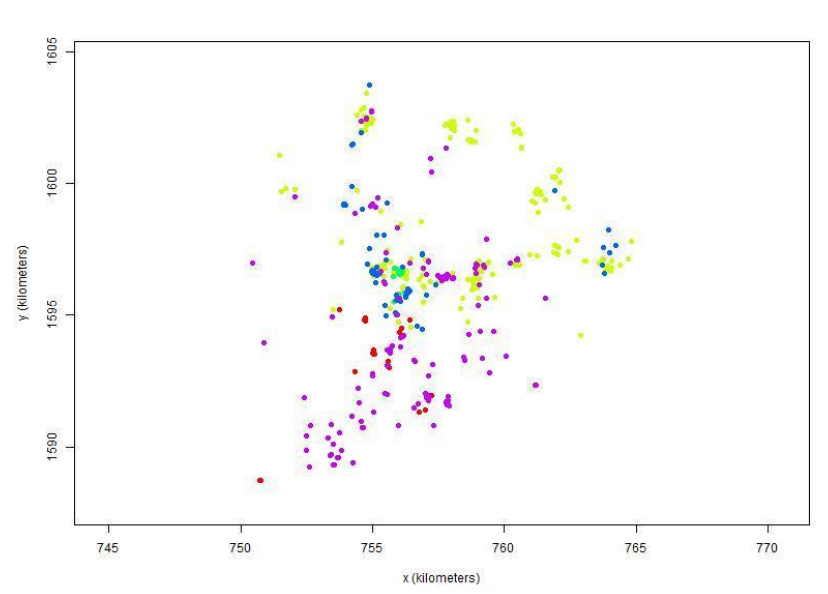

A

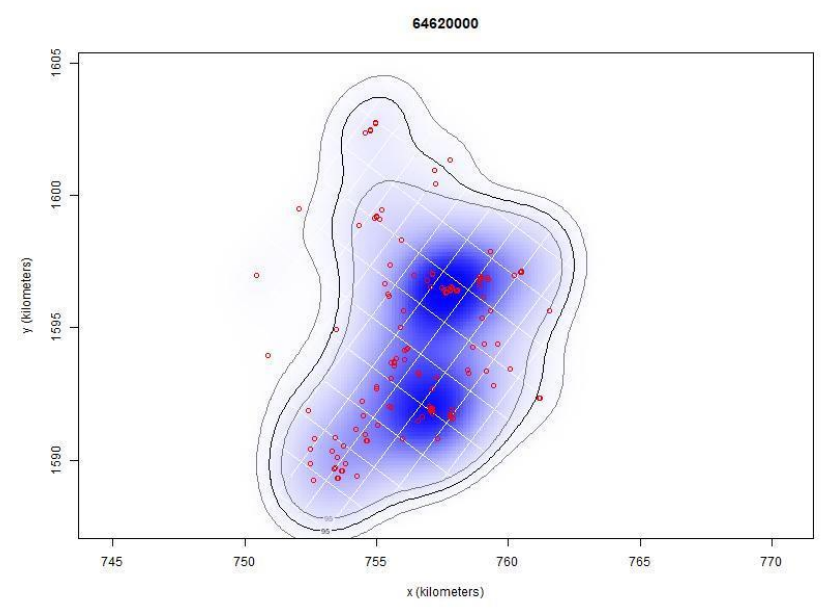

C

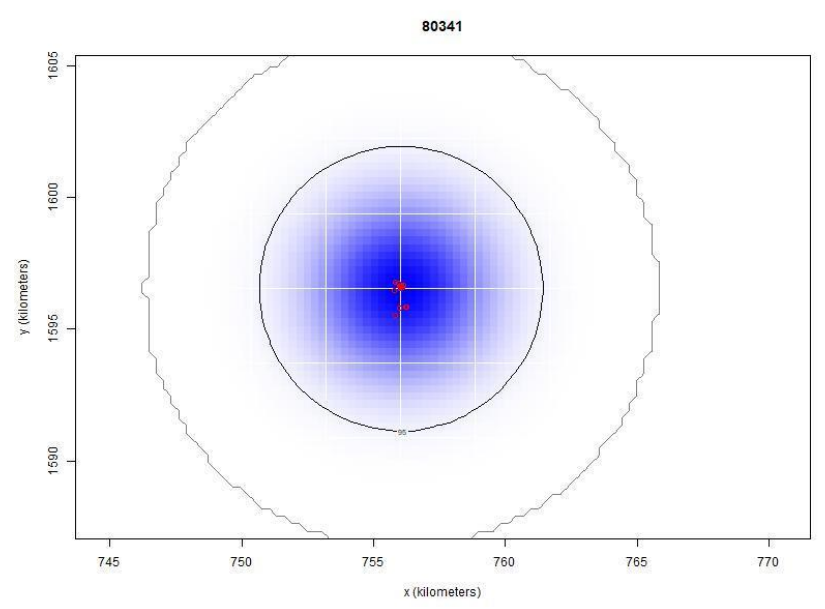

$\mathbf{E}$

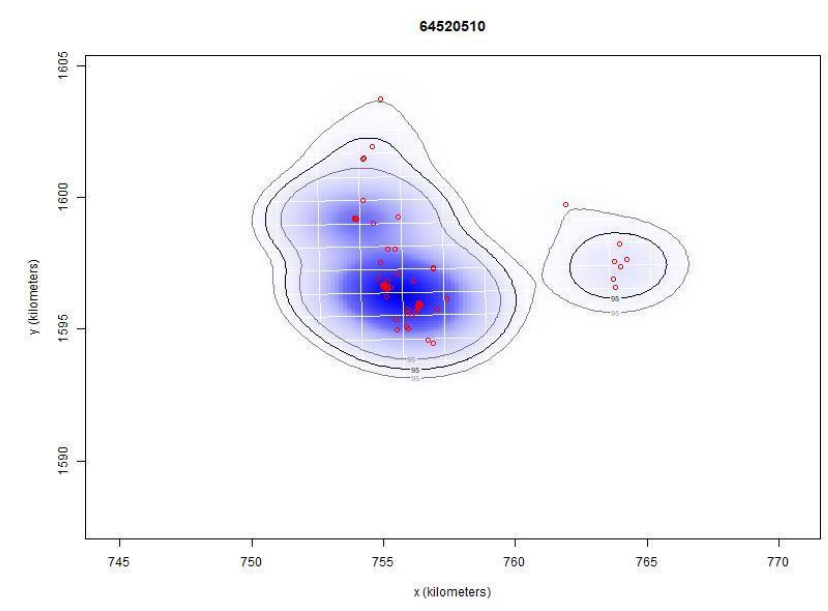

B

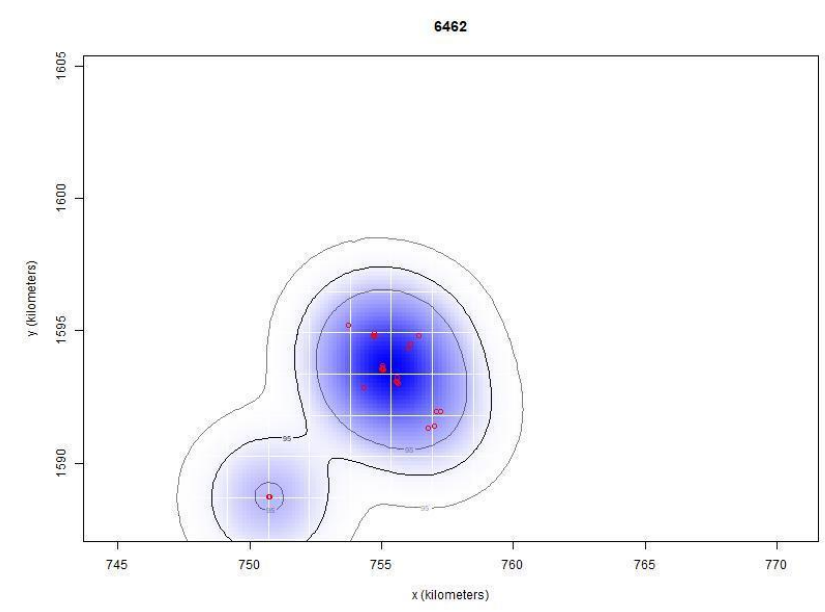

D

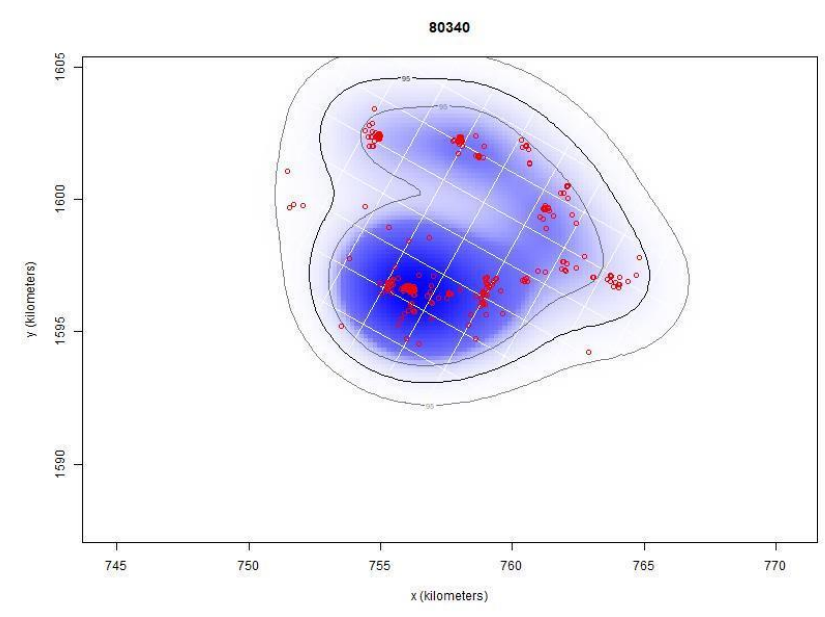

$\mathbf{F}$

Figure 2. Scatter of all GPS locations and home range characteristics for the 5 collared dholes individually in KYNP between 2017 and 2018 based on the AKDE method. A. All GPS locations for the 5 collared dholes in KYNP, Thailand, B. Home range characteristics for adult female dhole (AF 1) in KYNP analyzed using the AKDE method, C. Home range characteristics for adult female dhole (AF 2) in KYNP analyzed using the AKDE method, D. Home range characteristics for adult female dhole (AF 3) in KYNP analyzed using the AKDE method, E. Home range characteristics for adult male dhole (AM 1) in KYNP analyzed using the AKDE method, F. Home range characteristics for adult male dhole (AM 2) in KYNP analyzed using the AKDE method 


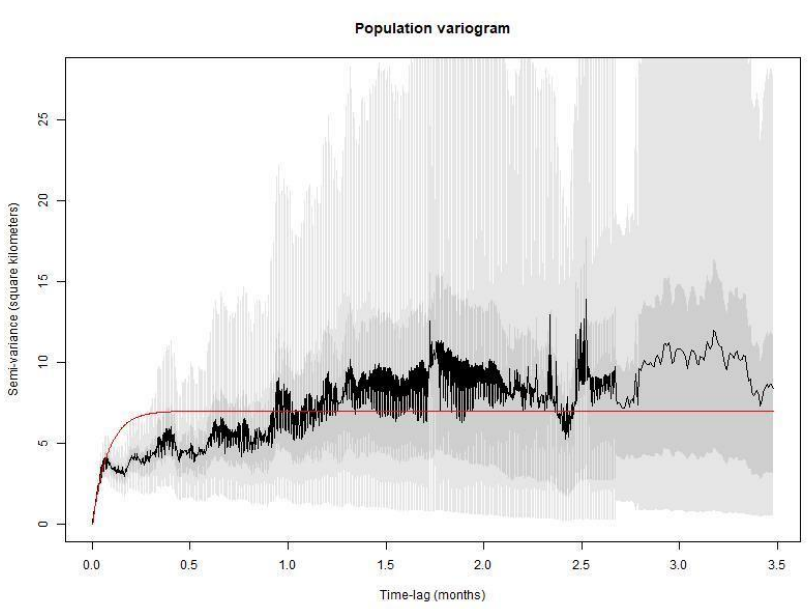

A

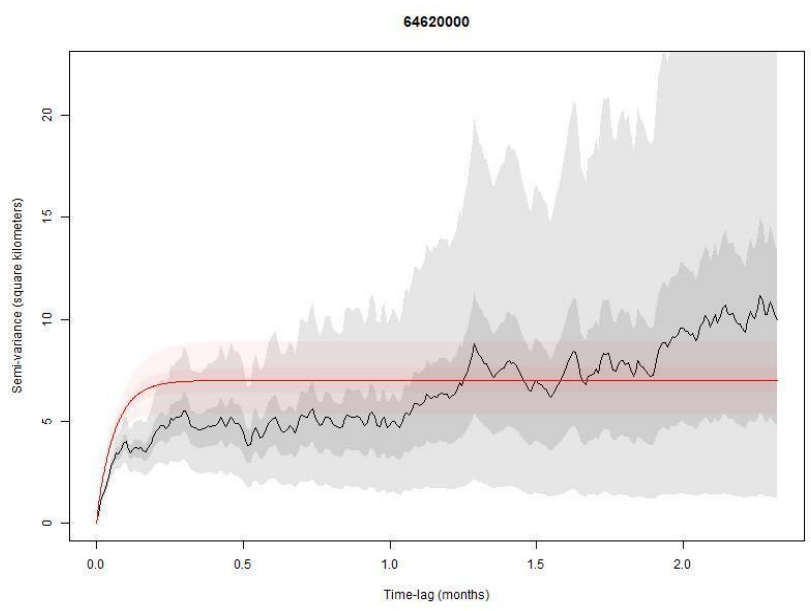

C

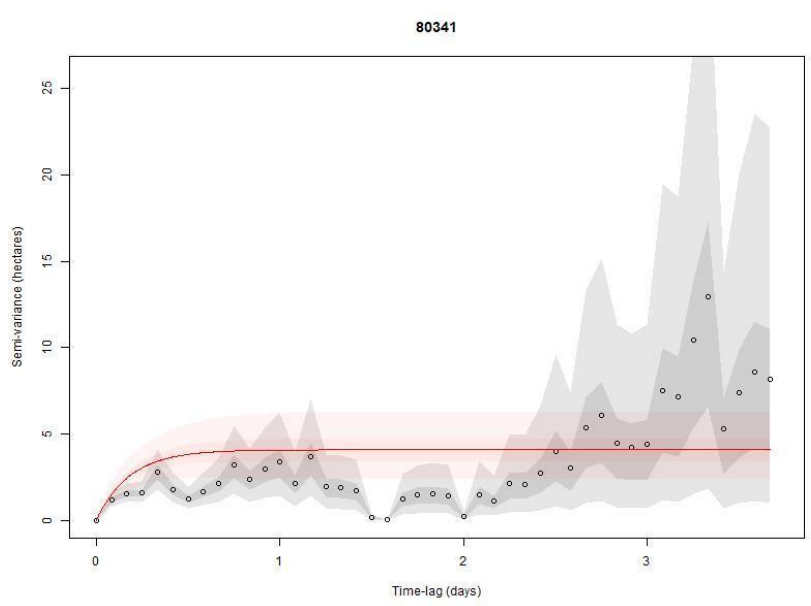

$\mathbf{E}$

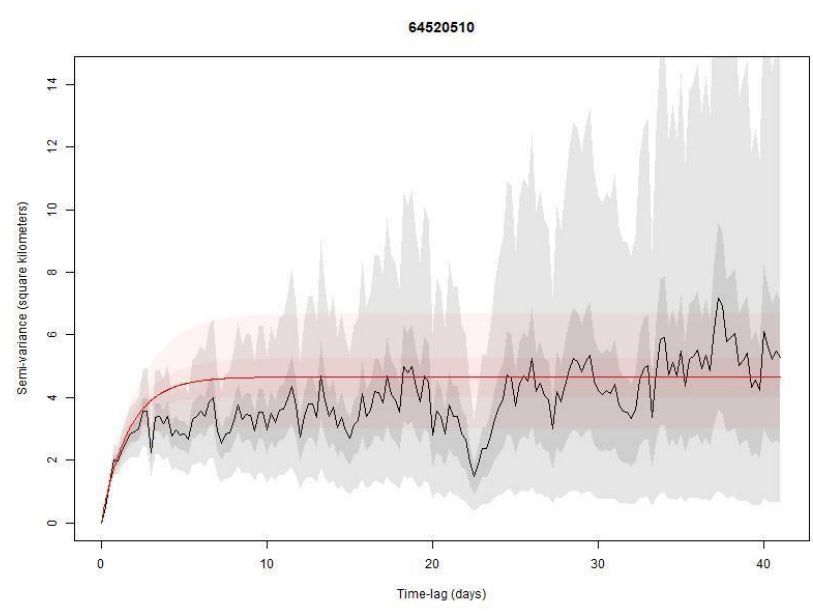

B

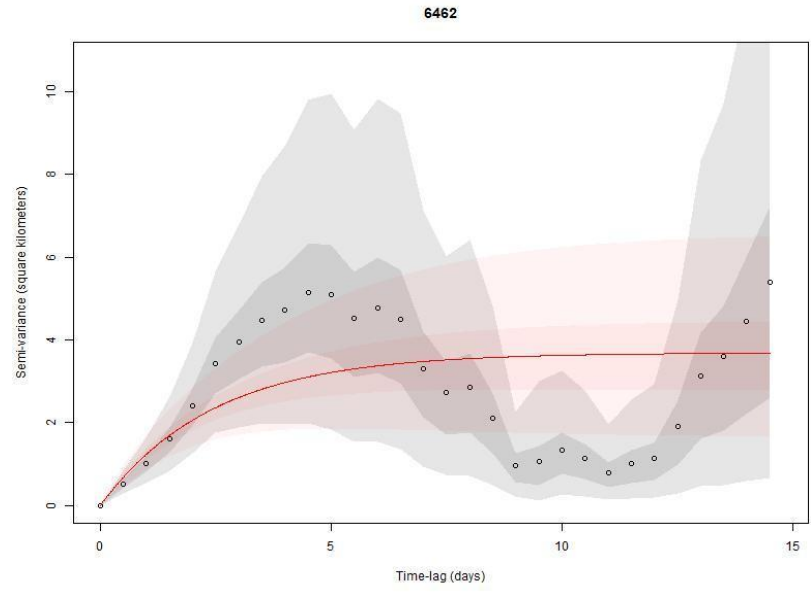

D

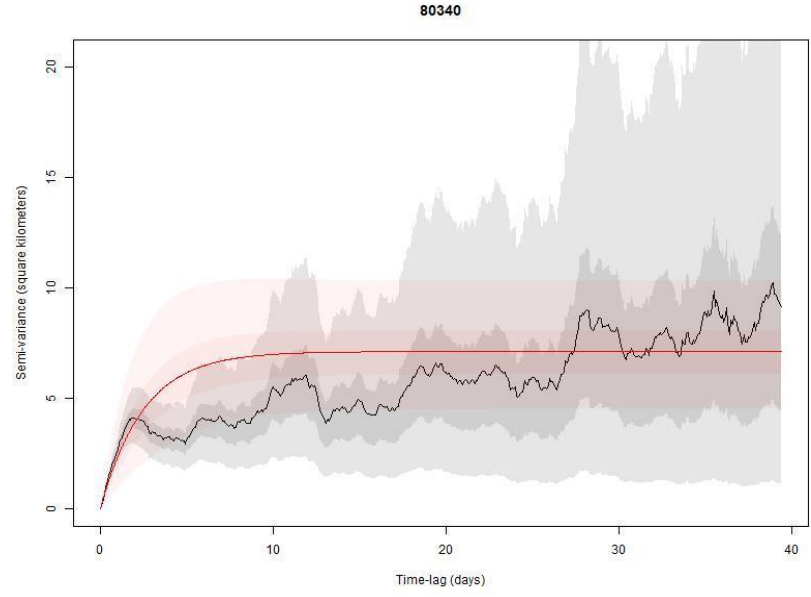

$\mathbf{F}$

Figure 3. Variogram of the five collared dholes between semi-variance and time lag, presented as comparative data for shorter time periods due to collar malfunctions. The complete semi-variogram, AF1, AF2, and AM2 are limited in scope to the first two fourth of the data since estimates in the last fourth of the semi-variogram has very large confidence intervals. Semi-variance and 95\% confidence intervals (CI) estimated from the standard error of the mean semi-variance were smoothed using a moving average over 20 lags. A. Variogram characteristics for all collared dholes. B. Variogram characteristics for adult female dhole (AF 1). C. Variogram characteristics for adult female dhole (AF2). D. Variogram characteristics for adult female dhole (AF 3). E. Variogram characteristics for adult male dhole (AM1). F. Variogram characteristics for adult male dhole (AM2) 
Table 2. The home ranges from Autocorrelated density estimation (AKDE) for 5 adult dholes, 3 adult females (AF) and 2 adult males (AM), each month in Khao Yai National Park, Thailand

\begin{tabular}{|c|c|c|c|c|c|c|c|c|c|c|c|}
\hline \multirow{2}{*}{ Month/year } & \multirow{2}{*}{$\begin{array}{l}\text { Age and } \\
\text { sex }\end{array}$} & \multirow{2}{*}{$\mathbf{N}^{1)}$} & \multirow{2}{*}{$\begin{array}{l}\text { Home range } \\
\text { crossing day (d) }\end{array}$} & \multirow{2}{*}{$\begin{array}{c}\text { Velocity } \\
\text { autocorrelated time } \\
\text { scale (minute) }\end{array}$} & \multirow{2}{*}{$\begin{array}{c}\text { Average distance } \\
\text { travelled } \\
(\mathbf{k m} / \mathbf{d a y})\end{array}$} & \multicolumn{3}{|c|}{$95 \% \mathrm{MCP}\left(\mathrm{km}^{2}\right)$} & \multicolumn{3}{|c|}{ 95\% AKDE $\left(\mathbf{k m}^{2}\right)$} \\
\hline & & & & & & $95 \%$ & $75 \%$ & $\mathbf{5 0 \%}$ & Low & Estimated & High \\
\hline Adult female dhole (AF1) & $\mathrm{AF}$ & & & & & & & & & & \\
\hline Feb $2017 *$ & $\mathrm{AF}$ & 55 & NA & NA & NA & 16.3 & 7.9 & 3.8 & 1.4 & 6.7 & 16.2 \\
\hline Mar $2017 *$ & $\mathrm{AF}$ & 67 & 0.9 & NA & NA & 35.7 & 15.3 & 7.2 & 14.9 & 26.1 & 40.5 \\
\hline Apr $2017^{*}$ & $\mathrm{AF}$ & 56 & 0.3 & NA & 10.2 & 41.5 & 14.2 & 6.5 & 27.0 & 38.7 & 52.4 \\
\hline Average (AF 1) & $\mathrm{AF}$ & & & & & 31.2 & 12.5 & 5.8 & 14.4 & 23.9 & 36.4 \\
\hline Adult female dhole (AF 2) & $\mathrm{AF}$ & & & & & & & & & & \\
\hline Feb $2017 *$ & $\mathrm{AF}$ & 36 & 2.4 & NA & NA & 24.4 & 12.1 & 62.3 & 23.4 & 50.0 & 86.6 \\
\hline Mar $2017 *$ & $\mathrm{AF}$ & 49 & 1.1 & NA & NA & 36.6 & 17.2 & 8.8 & 39.8 & 69.6 & 107.6 \\
\hline Apr $2017 *$ & $\mathrm{AF}$ & 43 & 2.1 & NA & NA & 32.4 & 152 & 6.9 & 37.6 & 83.9 & 148.5 \\
\hline May 2017 ** & $\mathrm{AF}$ & 40 & 1.0 & NA & NA & 44.9 & 18.0 & 7.7 & 65.3 & 103.4 & 150.2 \\
\hline Jun $2017 * *$ & $\mathrm{AF}$ & 62 & 0.7 & NA & NA & 18.7 & 8.6 & 4.2 & 31.7 & 60.7 & 98.8 \\
\hline Average (AF2) & $\mathrm{AF}$ & & & & & 31.4 & 41.6 & 18.0 & 39.6 & 73.5 & 118.3 \\
\hline Adult female dhole (AF 3) & $\mathrm{AF}$ & & & & & & & & & & \\
\hline Jan $2018 *$ & $\mathrm{AF}$ & 23 & 0.2 & NA & NA & 30.9 & 12.3 & 4.9 & 38.6 & 83.2 & 144.7 \\
\hline Feb $2018 *$ & $\mathrm{AF}$ & 24 & NA & NA & NA & 12.9 & 4.1 & 1.9 & 1.0 & 1.6 & 2.3 \\
\hline Average (AF3) & $\mathrm{AF}$ & & & & & 21.9 & 8.2 & 3.4 & 19.8 & 42.4 & 73.5 \\
\hline Adult male dhole (AM 1) & $\mathrm{AM}$ & & & & & & & & & & \\
\hline Feb $2018 *$ & $\mathrm{AM}$ & 37 & NA & NA & NA & 17.7 & 8.8 & 4.6 & 2.8 & 10.5 & 22.9 \\
\hline Mar $2018 *$ & $\mathrm{AM}$ & 153 & 2.5 & NA & NA & 24.6 & 11.6 & 5.2 & 29.3 & 70.2 & 128.5 \\
\hline Average (AM1) & $\mathrm{AM}$ & & & & & 21.2 & 10.2 & 4.9 & 16.1 & 40.4 & 75.7 \\
\hline Adult male dhole (AM 2) & $\mathrm{AM}$ & & & & & & & & & & \\
\hline Jan $2018 *$ & $\mathrm{AM}$ & 102 & 1.9 & NA & NA & 21.0 & 10.5 & 5.4 & 14.5 & 47.6 & 100.1 \\
\hline Feb $2018 *$ & $\mathrm{AM}$ & 167 & 0.9 & 48.7 & 19.3 & 37.4 & 14.7 & 5.3 & 55.5 & 97.6 & 151.2 \\
\hline Mar $2018 *$ & AM & 150 & 2.2 & NA & NA & 28.1 & 14.1 & 7.4 & 35.3 & 77.6 & 136.1 \\
\hline Apr $2018 *$ & $\mathrm{AM}$ & 40 & 0.1 & NA & 1.7 & 34.5 & 12.6 & 5.8 & NA & NA & NA \\
\hline \multirow{2}{*}{ Average (AM 2) } & $\mathrm{AM}$ & & & & & 30.3 & 13.0 & 6.0 & 35.1 & 74.3 & 129.1 \\
\hline & & 1104 & & & & & & & & & \\
\hline
\end{tabular}

Note: * denning period, $* *$ post-denning period, 1$)$ Number of telemetry locations 


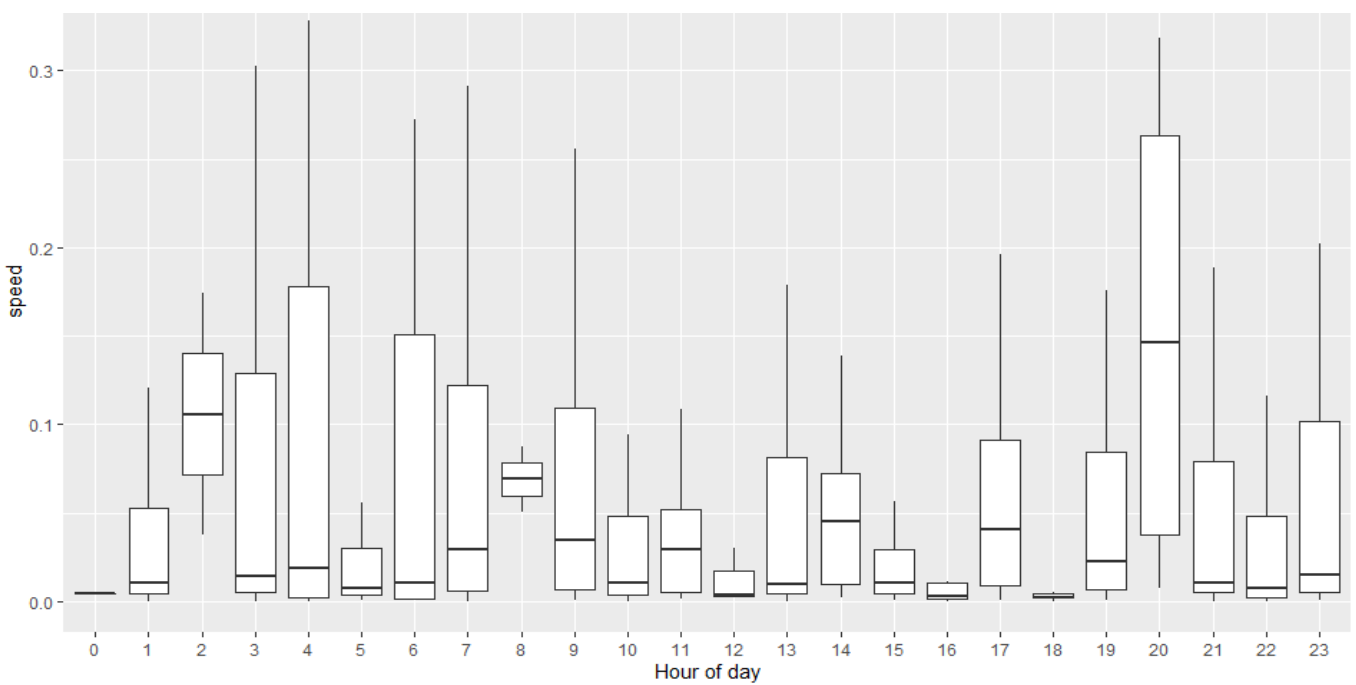

Figure 4. Diel activity analysis (2-hrs interval) of the collared dholes in Khao Yai National Park, Thailand
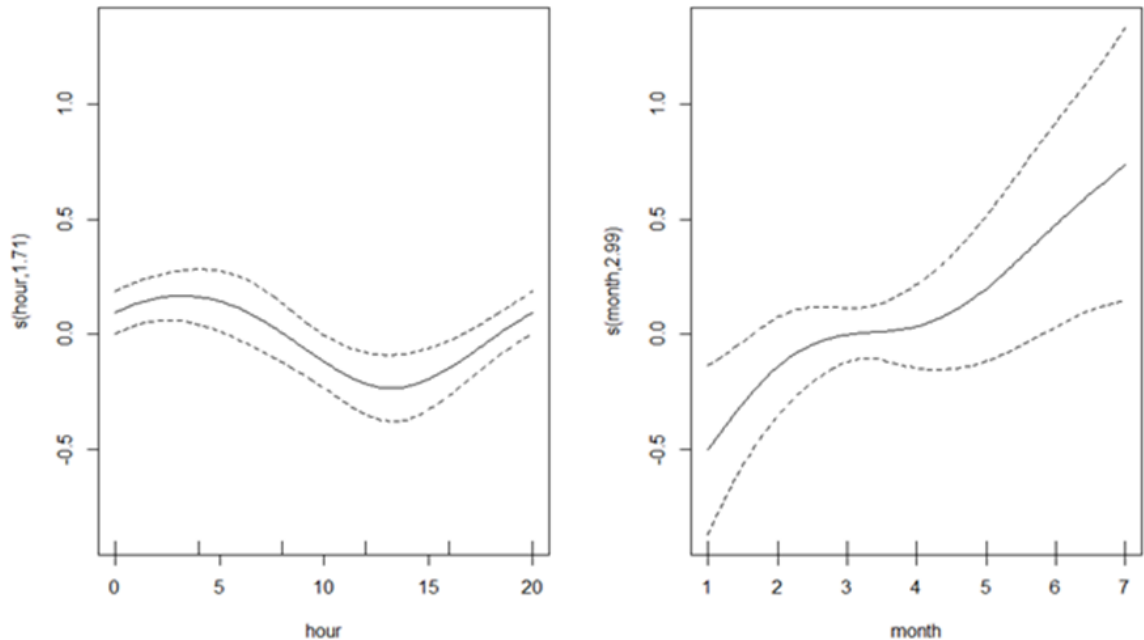

Figure 6. Fixed effects of GAMMs represent an hourly and monthly trend for diel activity pattern of GPS collared dholes. The solid line shows the average activity time in a day. Dashed lines show 95\% confidence interval.

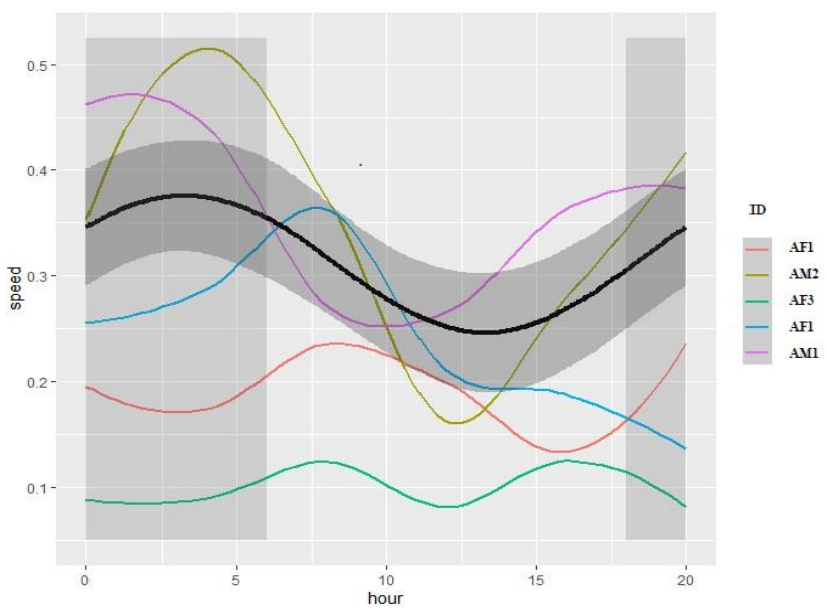

Figure 5. Predicted responses of movement rate from Generalised Additive Mixed Models (GAMM) using mgcv packageAutoregressive model of negative binomial family + applied cyclic cubic regression spline to make diel cycle with individual animals as a random effect on each spline. Grey shading represents night-time.

\section{Habitat selection pattern}

The space-use only model using step selection function by analyzing data for every individual dhole between the number of positions and habitat condition revealed that the overall number of positions represented the appearance of dholes, from the satellite signal mostly corresponded to the dry evergreen forest habitat, grassland, and mixed deciduous forest, respectively. The level of habitat utilization varied according to the different periods in a day, as shown in Figure 7.

Based on Figure 7 reveals that the highest portion of dholes' position, acquired from a satellite signal, was found in dry evergreen forest, grassland, and mixed deciduous forest, respectively. However, case-control linear logistic regression analysis considering coefficients in case of individual models between the number of positions and three types of habitats: mixed deciduous forest, grassland, and dry evergreen forest found that the distance from the position of dholes acquired from satellite signal was significantly related to the dry evergreen forest. Meanwhile, the distance from the position of dhole was 
significantly negative for grassland, likely meaning the dholes had increasing activities on grassland while using the mixed deciduous forest as a habitat.

The analysis of the coefficient in the case of the full model found that the mixed deciduous forest significantly affected the appearance of dholes. When involving the activity of dholes with the types of habitat, it was discovered that the mixed deciduous forest had a significantly negative effect on dhole activity. Further, the activity level of dhole was extremely low in the mixed deciduous forest, while grassland had a highly positive effect on dhole activity. Analysis using three factors including the condition of habitat, distance, and space use found that the distance had a highly significant effect on co-factors between the activity and mixed deciduous forest of dholes. This explains that the mixed deciduous forest is extremely important for dhole activities, as shown in Table 3.

\section{Discussion}

The results showed that the overall home range for the male dhole $\left(132.9 \mathrm{~km}^{2}\right)$ was approximately twice as large as that for the adult female dhole $\left(64.6 \mathrm{~km}^{2}\right)$. The average distance in the movement for the first female dhole during April was $10.2 \mathrm{~km} / \mathrm{day}$, while that for the second male dhole in February was $19.3 \mathrm{~km} /$ day. In the case of the overall analysis, only the second male dhole resulted in a distance of movement at $19.0 \mathrm{~km} /$ day based on the analysis of AKDE. The use of new analytical methods for movement data found each variable on space use and movement, with male dholes exhibiting larger home ranges and a higher probability of moving longer distances compared to females. The home range estimates using AKDE were larger when compared with MCP estimates calculated with the same data. The MCP method ignores autocorrelation and has been proven to underestimate the home range area when used for autocorrelated tracking data. AKDE accounts for autocorrelation in the data and adjusts home range estimates accordingly. An accurate estimate of the home range could offer vital insight into the ecological processes and provides a promising avenue for further investigation. We found the average distance of movement for the first female dhole was $10.2 \mathrm{~km} /$ day during April, while the second male dhole was $19.3 \mathrm{~km} /$ day during February. In the case of the overall analysis, only the second male dhole exhibited a distance of movement at $19.0 \mathrm{~km} /$ day based on the analysis of AKDE. This new finding concerning the size of dholes' home range and movement by using new analysis processes fills a gap in the knowledge about the species' ecology as well as contributing to long-term species management and conservation.

The study found that the size of the monthly habitat varied for individual female dhole according to the surrounding conditions and particular needs, though the range varied between $23.9-73.5 \mathrm{~km}^{2}$. At the same time, the size of the monthly habitat for male dhole was between 40.4-74.3 $\mathrm{km}^{2}$. There was no significant difference between the current size of the monthly habitat between male and female dhole.

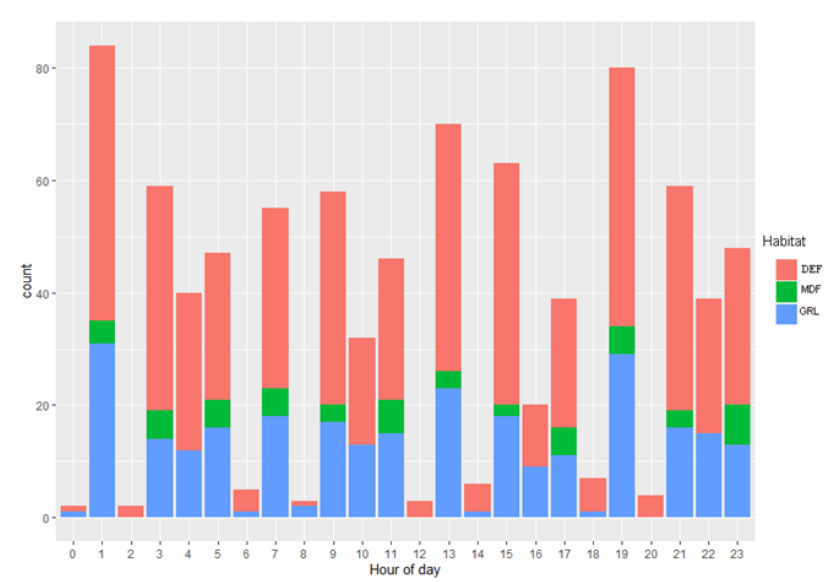

Figure 7. Summarised habitat selection based on GPS locations. Notes: pink color represents the dry evergreen forest; green was the mixed deciduous and blue was grassland

Table 3. Case-control linear logistic regression between the distance of the location and habitat types

\begin{tabular}{lll}
\hline Factors & $\begin{array}{l}\text { Coefficients } \\
\text { (individual models) }\end{array}$ & $\begin{array}{l}\text { Coefficients (full } \\
\text { model) }\end{array}$ \\
\hline MDF & - & $1.450(0.02)^{*}$ \\
GRL & - & $0.233(0.06)$ \\
DEF x activity & - & $-0.341(0.06)$ \\
MDF x activity & - & $-4.092(<0.01)^{* *}$ \\
GRL x activity & - & $1.348(<0.01)^{* *}$ \\
Distance-DEF & $1.565(0.04)^{*}$ & $0.860(0.29)$ \\
Distance-MDF & $-0.078(0.09)$ & $-0.092(0.08)$ \\
Distance-GRL & $-0.593(<0.01)^{* *}$ & $-0.558(<0.01)^{* *}$ \\
Distance-DEF & $-1.020(0.23)$ & $-0.178(0.86)$ \\
$x$ activity & & \\
Distance-MDF & $0.007(0.83)$ & $0.101(0.01)^{*} *$ \\
$x$ activity & & $-0.245(0.08)$ \\
Distance-GRL & $-0.114(0.30)$ & \\
x actity & &
\end{tabular}

$\mathrm{x}$ activity

Note: *significant p-value $<0.05$ (in parentheses), DEF: dry evergreen; MDF: mixed deciduous; GRL: grassland

However, the overall analysis found that the home range size for male dhole was roughly twice as large as that for female dhole. This explains that male dholes in nature have more activities than female dhole in terms of hunting and mating activities. It was noticeable from the movement of male dhole in a day, which was 19 kilometers/day compared to female dhole at 10 kilometers/day. Although this study considered the size of the monthly habitat, the data was not sufficient to cogently compare the home range size before, between, and after the denning period in Thailand. However, it was found from the analysis that the size of the monthly habitat for female dhole, from January to April, was smaller after April. This corresponds with the analysis of dhole activity from radio signals, which found augmentation in May. It also agreed with Durbin et al. (2004), who reported that the denning season of dhole was from December to April. The study result for the third mature female dhole was also agreeable. It was found that the average monthly habitat from January to April was 45.9 
$\mathrm{km}^{2}$, which grew to $82.0 \mathrm{~km}^{2}$ after the denning period. Investigation to understand the home range size of female dhole from January to April, the denning period as reported by Durbin et al. (2004), showed that the monthly average of the home range size was $50.4 \mathrm{~km}^{2}$ based on $95 \%$ AKDE, which was larger than the results gained from the study by Acharya et al. (2010) in India, which reported that the home range size during the denning period of male dhole in the Pench Tiger Reserve, India was $25.5 \mathrm{~km}^{2}$; females could not be studied according to the same report by Acharya et al. (2010). Based on the novel analysis method in this study, it was found that the collared dholes were mostly active during the early morning and after sunset. Meanwhile, Kawanishi and Sunquist (2008) and Majumder (2011) reported that dholes mostly hunted during the day time, especially in the morning and afternoon.

The results showed that dholes in the area were as active as tigers and leopards in India that hunt at night until morning (Karanth and Sunquist 2000). Ghaskadbi et al. (2016) reported that dholes at the Tadoba-Andhari Tiger Reserve, India have a crepuscular activity pattern, as found in the report by Nurvianto et al. (2015), who studied dholes on Java Island, Indonesia. Dholes, like other carnivorous animals, are sensitive to human disturbances (Karssene et al., 2017). Jenks et al. (2012) reported that dholes in Khao Ang Rue Nai Wildlife Sanctuary, located in the eastern part of Thailand, have low adaptability to areas with high human activity and are at a greater disadvantage than other species in dealing with habitat fragmentation. They also found that most dhole activities occurred during the daytime (Jenks et al. 2012). Based on the results of this study, dholes can adapt to recreational activity areas, but there must be no distractions that directly affect their survival. Our results were similar to those of Punjabi et al. (2017), who reported that anthropogenic disturbances had a negative influence on dhole existence. The dholes change their daytime activities to be more active before dawn and after dusk due to avoiding recreational activities. Moreover, dholes likely select habitats with higher densities of sambar (Jenks et al. 2012; Kamler et al. 2012) and muntjac (Kamler et al. 2012), which is a preferred prey species for dhole (Karanth and Sunquist 1995) such as those found around the KYNP head office. Thus, habitat improvement far from sites for human activity to promote the growth of the prey population is important for species conservation, while controlling recreational activities is necessary for the conservation of carnivorous wildlife. The results of this study could confirm the habitat selection of dhole that grassland was extremely important for activities, especially hunting. It was found that nearly all of the successful hunts by dhole during the study occurred in grassland. Therefore, the results showed that the activity of dhole and distance in grassland contrasted significantly. Even though a small portion of the mixed deciduous forest grows and blends with dry evergreen forest, after grassland, studying the habitat conditions found it is a highly important activity area of dhole for denning. Field investigation at the position where the radio signal was motionless for an extended period revealed that a cluster of the mixed deciduous forest was the main denning area of dhole. Almost all of the 13 dens for dholes were found in the mixed deciduous forest, where the canopy was not as dense as that of the dry evergreen forest. However, there was only one den where dhole pups were found. This could be attributed to the greatly contrary result for dhole activities in the mixed deciduous forest. Investigation focused on the denning and parenting of dhole at the site should be investigated further.

In conclusion, we used GPS collars to investigate the home range and movement of dholes at Khao Yai National Park during the period from early 2017 to 2018. Five dholes were collared and monitored, with three being female and two being male. The duration for tracking the radio signals of each dhole was 2-6 months due to collar malfunction or loss. The total number of locations that could receive radio signals was 1,104 locations from the five tracked individuals. This study calculated home range size using AKDE, which provides more accurate results for range when compared with the methods commonly used in the past. As hypothesized, we observed individual variability on space use and movement, with male dhole exhibiting larger home ranges and a higher distance of movement than females. Our study also found that dholes in the area were active during the early morning and after sunset. It also showed that the mixed deciduous forest was the main habitat in comparison to the grassland and dry evergreen forest. Dholes were more active in grassland, which they used as a hunting area, while the dry evergreen forest was a passageway between grasslands. Dholes preferred the mixed deciduous forest for denning as it was less dense than the dry evergreen forest. The recommendation for overseeing the population of dhole at the site included the management of grasslands integrated with the conservation of clusters of mixed deciduous forest areas for dhole activities and the maintenance of dhole populations. Future studies should assess the correlation between Khao Yai National Park and conservation areas in Dong Phayayen-Khao Yai to enhance the potential of the sites for the long-term conservation of the population.

\section{ACKNOWLEDGEMENTS}

The author would like to thank the Director of National Parks, Wildlife and Plant Conservation Department (DNP), Dr. Songtam Suksawang, the former Director of the National Park Office, DNP, Dr. Saksit Simcharoen, Director of the Wildlife Research Group, and the Dean of the Faculty of Forestry, Kasetsart University, Thailand for supporting this study. This study is financially supported by Earthwatch Institute, USA. The supportive fund for Ph.D. students of the Center for Advanced Studies in Tropical Natural Resources, Kasetsart University,.

\section{REFERENCES}

Acharya BB, Johnsingh AJT, Sankar K. 2010. Dhole telemetry studies in Pench Tiger Reserve, central India. Telemetry Wildlife Sci 13: 69-79. Allen AM, Singh NJ. 2016. Linking movement ecology with wildlife management and conservation. Front Ecol Evol 3: 155. 
Asa CS, Valdespino C. 1998. Canid reproductive biology: integration of proximate mechanisms and ultimate causes. Am Zool 38: 251-259.

Bekoff M. 1984. Social play behavior. Bioscience 34: 228-233.

Calcagno V. 2020. Package 'glmulti'. McGill University, Canada. www.cran.r-project.org/web/packages/glmulti/glmulti.pdf

Calabrese JM, Fleming CH, Gurarie E. 2016. Application ctmm: An R package for analyzing animal relocation data as a continuous-time stochastic process. Methods Ecol Evol 7: 1124-1132. DOI: 10.1111/2041-210X.12559.

Davidar ERC. 1974. Observation at the dens of the dhole or Indian wild $\operatorname{dog}$ (Cuon alpinus). J Bombay Nat Hist Soc 71: 183-187.

Durbin LS, Venkataraman A, Hedges S, Duckworth W. 2004. Dhole (Cuon alpinus). In: Sillero-Zubiri, C, Hoffmann M, Macdonald DW (eds). Canids: Foxes, Wolves, Jackals and Dog: Status Survey and Conservation Action Plan. IUCN/SSC Canid Specialist, Gland, Switzerland, and Cambridge, UK

Fleming CH, Fagan WF, Mueller T, Olson KA, Leimgruber P, Calabrese JM. 2015. Rigorous home range estimation with movement data: a new autocorrelated kernel density estimator. Ecology 96: 1182-1188. DOI: $10.1890 / 14-2010.1$

Fleming CH, Calabrese JM. 2017. A new kernel density estimator for accurate home-range and species-range area estimation. Methods Ecol Evol 8: 571-579.

Fortin D, Beyer H, Boyce MS, Smith DW, Mao JS. 2005. Wolves influence elk movements: behavior shapes atrophic cascade in Yellowstone National Park. Ecology 86: 1320-1330.

Ghaskadbi P, Habib B, Qureshi Q. 2016. A whistle in the woods: an ethogram and activity budget for the dhole in central India. J Mammal 97(6): 1745-1752

Gregory T. 2017. Home range estimation. In: Bezanson M, MacKinnon KC, Riley E, Campbell CJ, et al. (eds.) The International Encyclopedia of Primatology. Wiley, Hoboken.

Gutema TM. 2015. Wildlife radiotelemetry: use, effect and ethical consideration with emphasis on birds and mammals. Intl J Sci Basic App. Res 24(2): 306-313.

Harestad AS, Bunnel FL. 1979. Home range and body weight-a reevaluation. Ecology 60 (2): 389-402.

Hinton JW, Proctor C, Kelly MJ, van Manen FT, Vaughan MR, Chamberlain MJ. 2016. Space use and habitat selection by resident and transient red wolves (Canis rufus). PLoS One 11: e0167603. DOI: 10.1371/journal.pone.0167603

IUCN. 2019. Dong Phayayen-Khao Yai Forest Complex. www.iucn.org/asia/thailand/countries/thailand/dong-phayayen-khaoyai-world-heritage-site

Johnsingh. 1979. Ecology and behavior of the dhole or Indian wild Dog, Cuon alpinus Pallas 1811, with Special Reference to Predator: Prey Relations at Bandipur. [Dissertation], Madurai Kamaraj University, Madurai, India.

Jenks KE, Songsasen N, Leimgruber P. 2012. Camera trap records of dholes in Khao Ang Rue Nai Wildlife Sanctuary. Canid Specialist Group's Canid News. www.canids.org/canidnews/15/Camera_trap_records_of_dholes_in_T hailand.pdf.

Karanth KU, Sunquist ME. 1995. Prey selection by tiger, leopard and dhole in tropical forests. J Anim Ecol 64(4): 439-450.

Kamler JF, Johnson A, Vongkhamheng C, Bousa A. 2012. The diet, prey selection, and activity of dholes (Cuon alpinus) in northern Laos. $\mathrm{J}$ Mammal 93: 627-633.

Kamler JF, Songsasen N, Jeks K, Srivathsa A, Sheng L, Kunkel K. 2015. Cuon alpinus. The IUCN Red List of Threatened Species 2015:
e.T5953A72477893.

DOI:

10.2305/IUCN.UK.2015-

4.RLTS.T5953A72477893.en

Karanth KU, Sunquist ME. 2000. Behavioural correlates of predation by tiger (Panthera tigris), leopard (Panthera pardus) and dhole (Cuon alpinus) in Nagarahole, India. J Zool 250(2): 255-265.

Karssene Y, Chammem M, Khorchani T, Nouira S, Li F. 2017. Global warming drives changes in carnivore communities in the North Sahara Desert. Clim Res 72: 153-162.

Kawanishi K, Sunquist ME. 2008. Food habits and activity patterns of the Asiatic golden cat (Catopuma temminckii) and dhole (Cuon alpinus) in a primary rainforest of Peninsular Malaysia. Mammal Stud 33: 73177.

Majumder. 2011. Prey Selection, Food Habits and Population Structure of Sympatric Carnivores Tiger (Panthera tigris tigris), leopard (Panthera pardus) and Dhole (Cuon alpinus) in Pench Tiger Reserve, Madhya Pradesh, India. [Dissertation]. Saurashtra University, Gujrat, India.

Mohr EO. 1947. Table of equivalent populations of North American small mammals. Am Midl Nat 37: 223-249.

Mohr EO, Stumpf WA. 1966. Comparison of methods for calculating areas of animal activity. J Wildl Manag 30: 293-304.

Morato RG, Stabach JA, Fleming $\mathrm{CH}$, et al. 2016. Space use and movement of a neotropical top predator: the endangered jaguar. PLoS ONE 11(12): e0168176. DOI: 10.1371/journal.pone.0168176

Ngoprasert D, Gale GA. 2019. Tiger density, dhole occupancy, and prey occupancy in the human-disturbed Dong Phayayen-Khao Yai Forest Complex, Thailand. Mamm Biol 95: 51-58.

NPRD (National Parks Research and Innovation Development Center). 2017. Attitudes and Opinions of Thai Tourists towards the Conservation of Crocodiles in Khao Yai National Park. National Parks Wildlife and Plant Conservation Department, Nakorn Ratchasima Province, Thailand. [Thai]

Nurvianto S, Imron MA, Herzog S. 2015. Activity patterns and behaviour of denning dholes (Cuon alpinus) in a dry deciduous forest of East Java, Indonesia. Bull Environ Pharmacol Life Sci 4 (12): 45-54.

Punjabi GA, Edgaonkar A, Srivathsa A, Ashtaputre S, Rao MK. 2017. Distribution of the dhole in its northern range limits in the Western Ghats, India. Canid Biol Conserv 20: 7-13.

R Core Team. 2017. R: A language and environment for statistic computing. R Foundation for Statistical Computing, Vienna. www.Rproject.org/.

Signer J, Balkenhol N. 2015. Reproducible home ranges (rhr): A new, user-friendly $\mathrm{R}$ package for analyses of wildlife telemetry data. Wildl Soc Bull 39 (2): P358-363. DOI: 10.1002/wsb.539.

Sosnovskii IP. 1967. Breeding the red dog or dhole Cuon alpinus at Moscow Zoo. Intl Zoo Yearb 7: 120-122.

Srivathsa A, Karanth KK, Jathanna D, Kumar NS, Karanth KU. 2014. On a dhole trail: examining ecological and anthropogenic correlates of dhole habitat occupancy in the Western Ghats of India. PLoS ONE 9(6): e98803. DOI: 10.1371/journal.pone.0098803

Tamminga M, MacKenzie L, Embick D. 2016. The dynamics of variation in individuals. Linguist Var 16(2): 300-336.

Venkataraman AB, Arumugam R, Sukumar R. 1995. The foraging ecology of dhole (Cuon alpinus) in Mudumalai Sanctuary, southern India. J Zool 237: 543-561.

Wood S. 2019. Package 'mgcv': Mixed GAM Computation Vehicle with Automatic Smoothness www.cran.uib.no/web/packages/mgcv/mgcv.pdf
Estimation. 